\title{
Interoperability in Defense Communications
}

\author{
GILBERT E. LAVEAN, MEMBER, IEEE
}

\begin{abstract}
This paper addresses the need for interopínerability between communications systems that support the U.S. Defense community (tactical and strategic), U.S. Civil Government community, and Allied National communities. A spectrum of interoperability is presented that permits system objec..ves to be stated in more precise terms and also provides a basis for cost versus benefit analysis. A set of preliminary secure voice interoperability objectives, in terms of the spectrum of interoperability, is also developed in this paper. The results of the Worldwide Secure Voice Architecture (WWSVA) are also briefly described. The paper includes an Appendix that briefly describes the major systems that were included for study in the WWSVA.
\end{abstract}

\section{THE CHANGING MISSION FOR GLOBAL COMMUNICATIONS}

$\mathbf{F}$ OR many reasons, U.S. Forces overseas have been reduced. To many observers, the obvious result of this drawdown should be reduced DoD communications needs overseas. However, the relationship between force levels and supporting communications is more complex than it appears. Changes in missions and the need to show U.S. presence in the face of an expanding Soviet influence have resulted in the need to maintain, and in some cases increase, the volume of DoD worldwide communications. In addition, other new missions are establishing demands that are beyond the capability of current communications systems.

The evolving concept of controlled response also places additional severe demands on DoD communications. In particular, communications in support of command and control functions must operate efficiently to enable direction of surviving forces for counterattack. Therefore, these global command and control communications networks must be considered as prime targets. Of course, no single communications capability is adequately robust to withstand a direct attack. Therefore, it is necessary to capitalize on the aggregate capability that is afforded by intelligently combining the assets of existing and planned systems. These systems include advanced satellite systems, commercial systems, NATO systems, and the diverse capabilities that exist within the DoD. The problem of "intelligently combining" these resources is the subject of several DoD studies recently completed or currently underway.

\section{BACKGROUND}

Historically, communications have either been considered as separate systems (not part of weapons systems) or as afterthoughts, thus resulting in frequent mismatches between communications systems and weapons systems. In the recent

Manuscript received January 15, 1980.

The author is with the Defense Communications Engineering Division, Defense Communications Agency, Reston, VA 22090. past, the consequences of allowing a confrontation to get out of hand and develop into an exchange of nuclear weapons has resulted in high level interest in controlling incidents that may seem trivial to most military commanders. This "interference" by the National Command Authorities (NCA) (the President, Secretary of Defense, and/or legal successor) has been referred to as the "President to the Fox Hole Syndrome."

Fig. 1 shows the chain of command that could be expected to manage day-to-day military operations. Normally, only a small portion of the database is passed to the next higher level of command, and only exceptional decisions are made above the immediately affected command level. Fig. 2 indicates the occurrence of an incident that has required a "President to the Fox Hole" connectivity. The figure shows that several levels of command could be bypassed. This bypassing process could introduce several problems: 1) an intermediate level could be giving conflicting orders, 2) additional data and experience reside at the intermediate command levels and could be useful in any decision process, and 3 ) if this procedure occurs frequently, it will destroy morale. Therefore, to the highest degree possible, it is essential to include the intermediate levels of command in the conference established to respond to these incidents. The inclusion of these intermediate levels of command in the conference is shown by the horizontal dashed lines. Providing multiple connectivities of this nature, over a sustained time interval, is one of the severest demands that can be placed on an aggregate communications capability.

It should be stressed that the high level interest in an individual encounter of this type would disappear if a war actually develops; however, the capability to establish and maintain such a connectivity is and will probably remain an important aspect of controlled response and crisis management. It is particularly important that command, control, and communications $\left(\mathrm{C}^{3}\right)$ systems and procedures be adaptable to rapidly changing situations ranging from day-to-day activities through crises (as indicated above) to conventional and nuclear warincluding a surprise attack on the United States. The interrelationship of force postures, levels of conflict, and the command and control function required at each level is illustrated in Fig. 3 [1]. To achieve end-to-end connectivity, from the highest level authority to site commanders, requires interconnecting many communications systems that were designed to accomplish other primary missions, as shown in Fig. 4 [2], [3]. In the past, incompatibilities between systems have resulted in serious delays in establishing the desired connectivities during specific incidents (e.g., S.S. Liberty).

Fig. 5 shows the interrelationships of the systems that could be used to support such an incident [4]. It may be necessary to provide concurrent connectivities to a Mayaguez, a joint contingency party, a fleet commander, Subic Bay, CINCPACFLT, CINCPAC, the Joint Chiefs of Staff, and the 


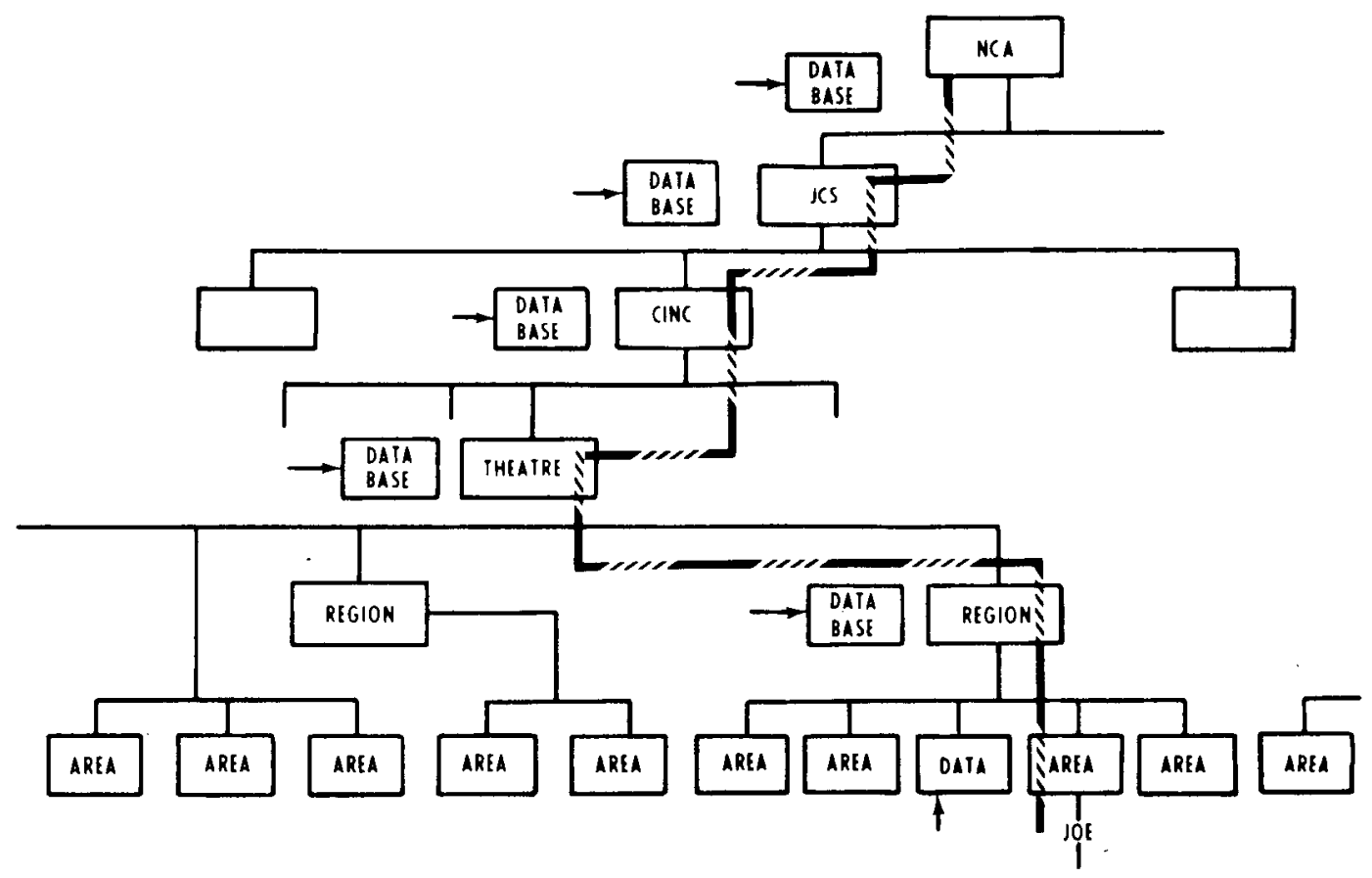

Fig. 1. DoD chain of command.

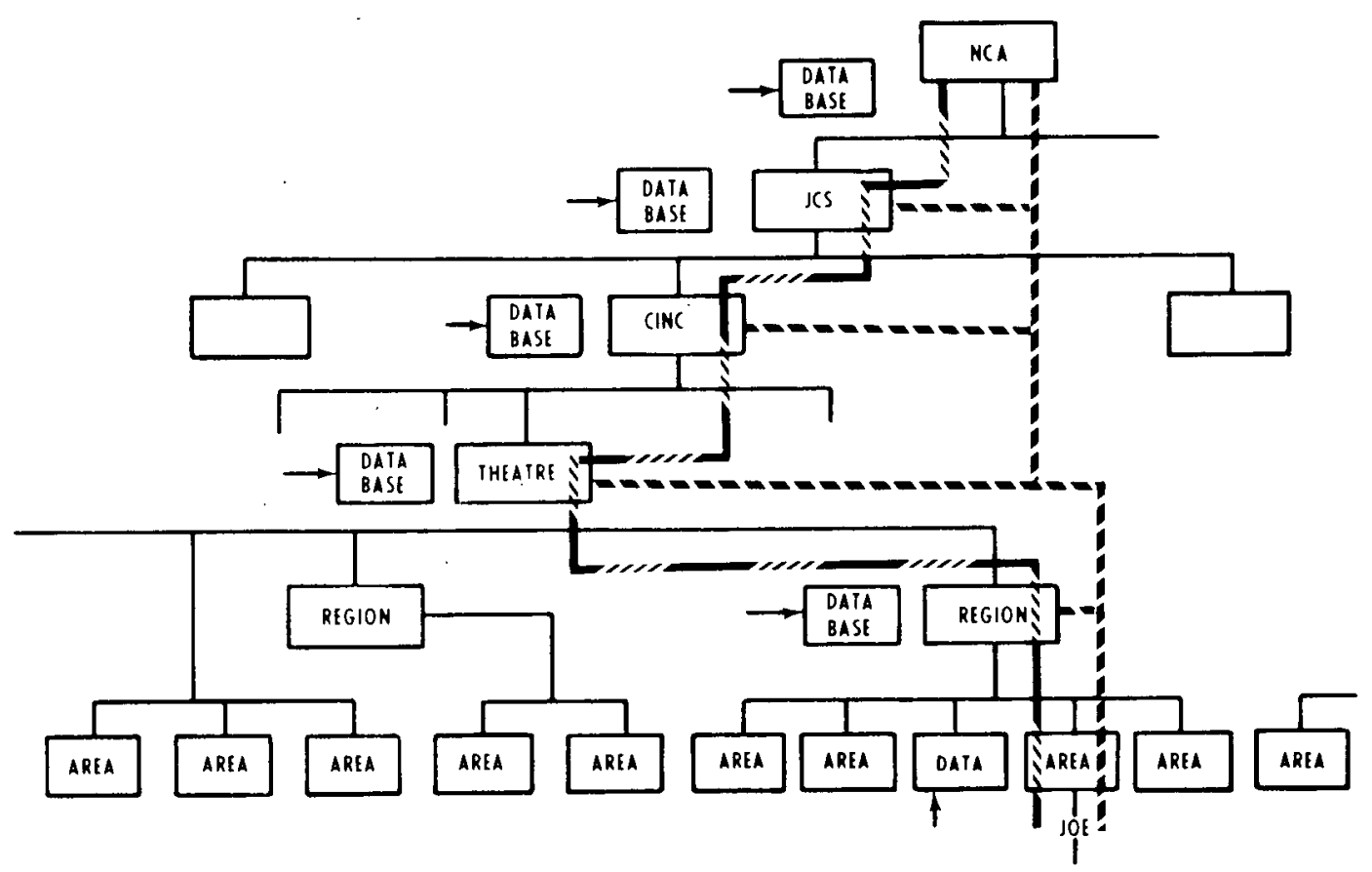

Fig. 2. President to the Fox Hole connectivity.

Secretary of Defense. The Defense Communications System (DCS) provides most of the long haul communications for these connections, but tactical systems and access lines are also included, and for the case of a commercial ship, it may be necessary to include civilian radio nets and State Department participation. Obviously, other sources of intelligence will also be used when available. Resolving these interoperability problems has been a primary reason for the Office of the Secretary of Defense to undertake several architectural efforts and joint programs. These communications architectures are useroriented and examine the needed capability on an end-to-end basis across management boundaries. The results of these analyses identified interoperability problems associated with current and planned systems and established functional capabilities and standards for future systems.

The coordination problems associated with developing interoperable communications systems within the United States environment is probably more complicated than within other countries. This is due to the autonomy of the many organizations involved. The commercial telecommunications networks within the United States are not managed by a Ministry of Telecommunications that has responsibility for both military 
POSTURE OF FORCES

LEVELS OF MCTIVITY C' SUPPONT FUNCTION REQUIRED C' CAPABILTY

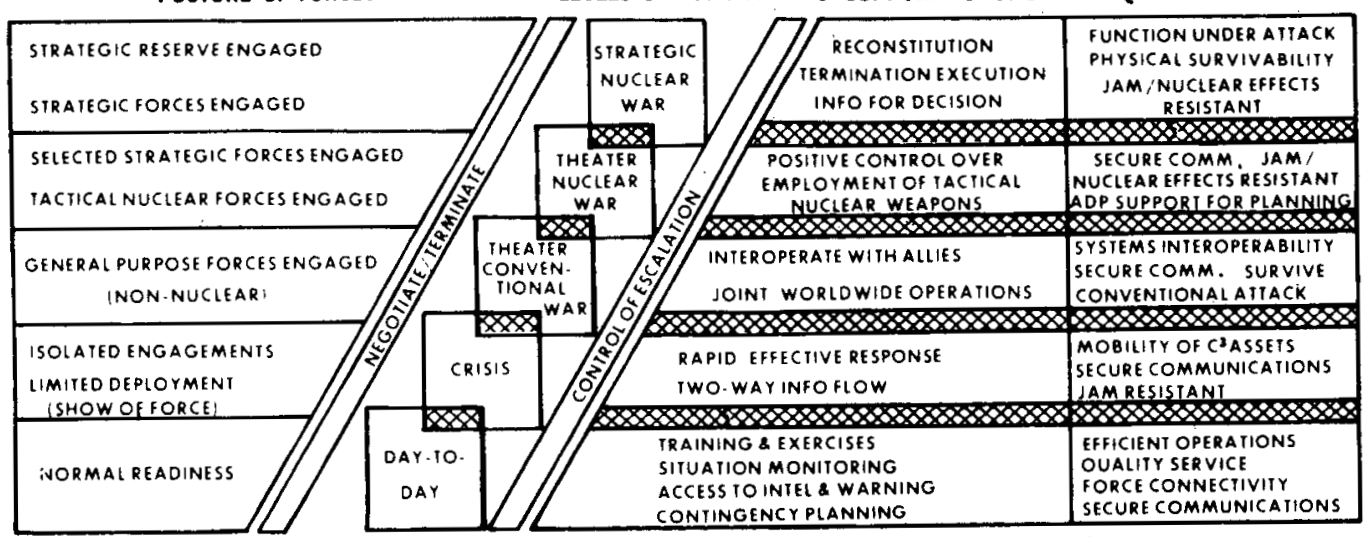

Q8. areas INDICAIE IRANSITION BETWEEN LEVELS CAPABILITIES IN THESE AREAS ARE KEY IO SMOOTH ORDERLY TRANSITION.

Fig. 3. The changing role of $\mathrm{C}^{3}$ in escalation control.

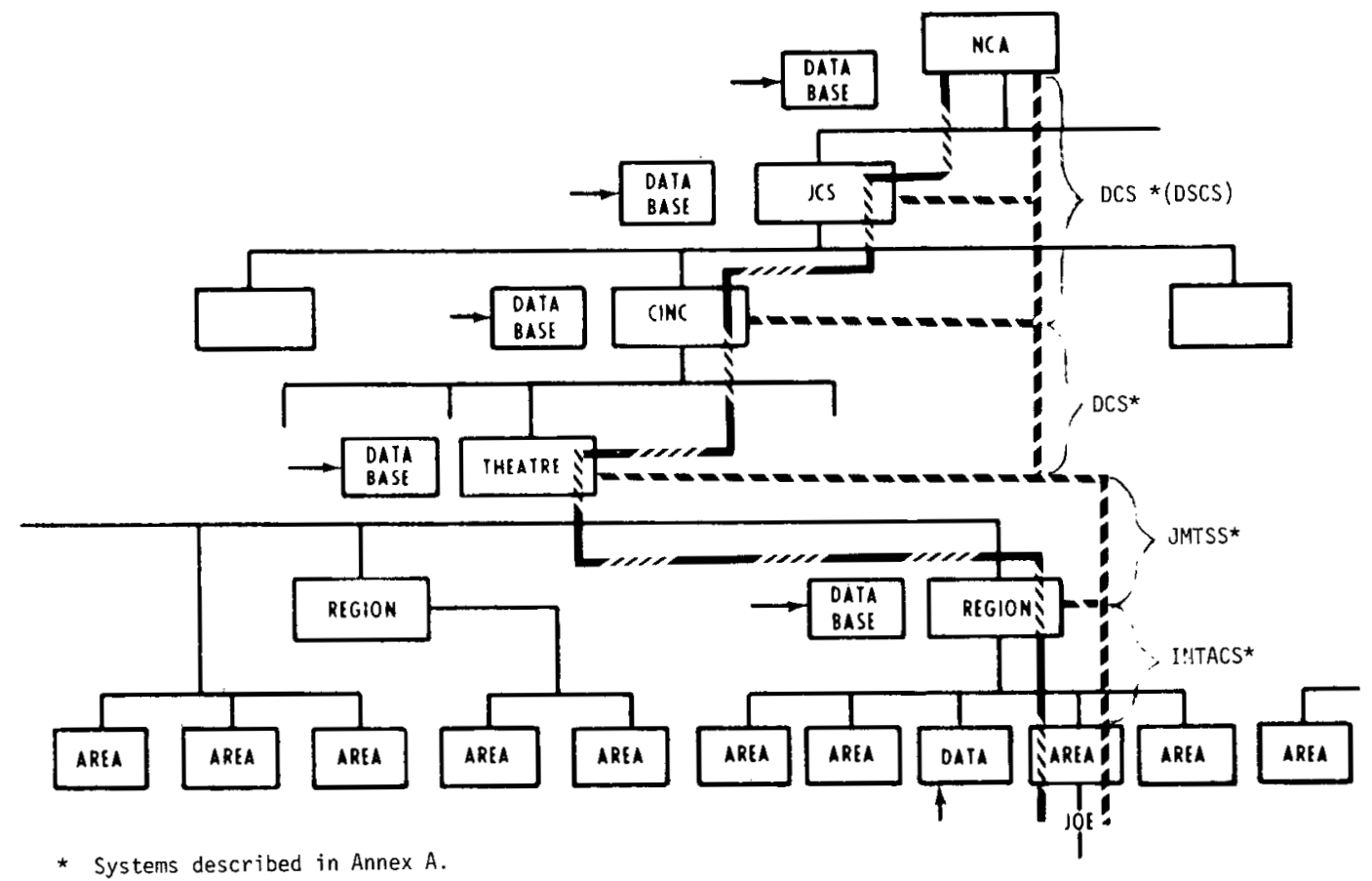

Fig. 4. Communication systems in support of $\mathrm{C}^{2}$.

and civilian telecommunications, as is the case in many other nations. In the United States, there are several common carriers, many competing manufacturers, and even within the DoD there are independent communications systems. Therefore, in addition to normal technical interface problems, there are significant policy issues relating to management and control.

The architectural efforts have indicated the lack of a commonly accepted definition for interoperability which has led the Defense Communications Agency (DCA) to develop a definition of a spectrum of interoperability. This detailed definition of interoperability will allow system interoperability objectives to be stated in more specific terms. Section III discusses the seven levels of interoperability, including technical and management/control considerations, and applies the spectrum concept to a specific example.
The DoD has historically divided communications into strategic and tactical systems with some command and control communications crossing over the boundary between the two tealms. However, recent usage of communications in conflicts, together with the rapid changes in supporting technology, have made it difficult to differentiate between strategic and tactical communications. The need to readily cross over from the strategic to the tactical realm to accomplish the "President to the Fox Hole" connectivities has also caused the justification for such a boundary to be questioned, particularly from a technical standpoint. The Worldwide Military Command and Control System (WWMCCS) has been established to overcome any technical interface issues that would limit critical command-and control-related communications. When the need to provide security and survivability for these essential connectivities is considered, the interface problems become even 


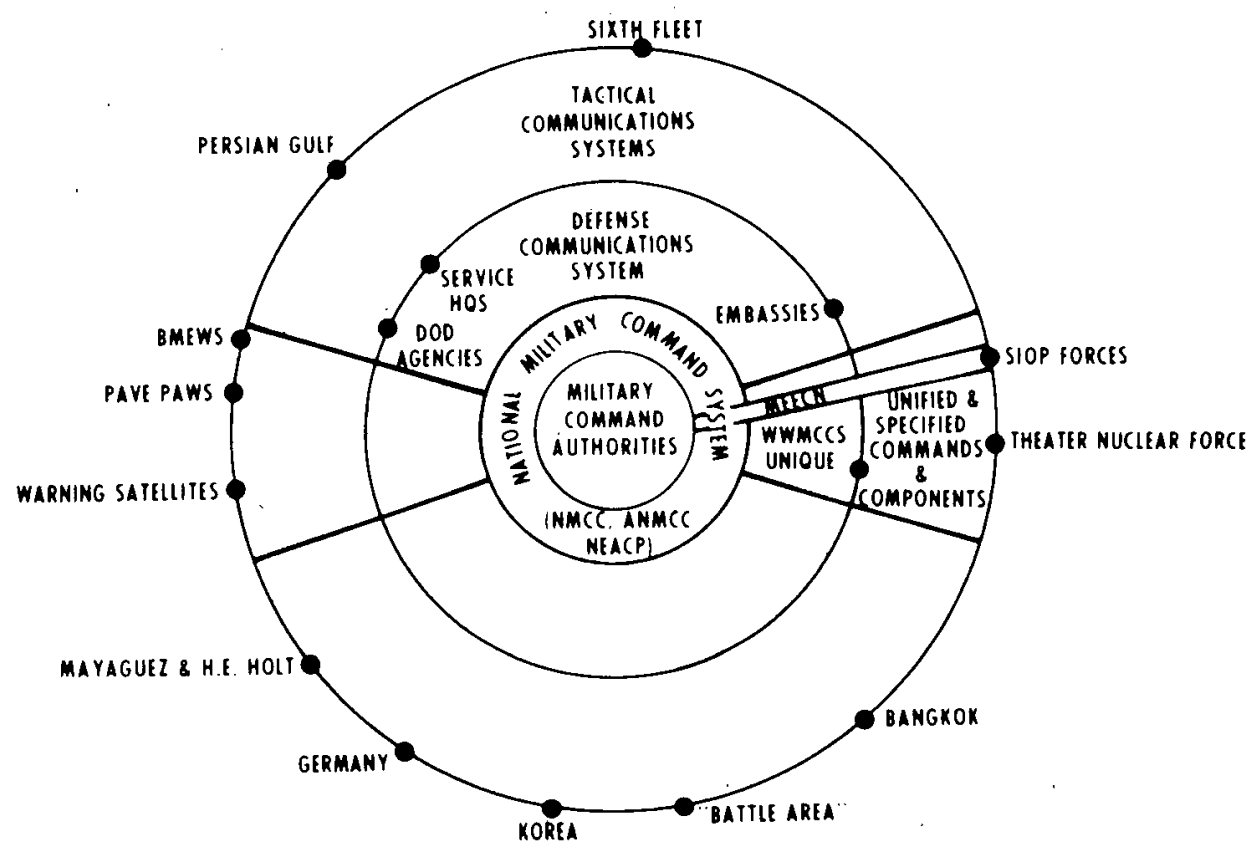

Fig. 5. Worldwide military command and control network.

more difficult. However, advances in state-of-the-art technology are helping to find answers to these difficult problems.

\section{INTEROPERABILITY CONSIDERATIONS}

The two most important factors constraining interoperability are technical interfaces and management/control philosophies. Technical interface possibilities range from: 1) it is impractical to interface user communities (i.e., HY-2 and ELCROVOX, two narrow-band secure voice digitizers which use different processing techniques);2) it is feasible to develop an interface box to allow interoperation; 3 ) one or both system equipments can be redesigned to allow connection between systems without having to utilize interface boxes; and 4) if both systems use common equipment, there are no technical interface problems.

Management/control possibilities range from: 1) complete independence between systems (i.e., requires two phones for a subscriber who is a member of both communities); 2) memorandum of understanding to share resources; 3 ) agreement for subscribers to talk to one another with no impact on individual system; 4) agreement for subscribers to talk to one another and it is important to the mission (i.e., survivability considerations), but retain individual prerogatives; 5) willingness to accept significant impact on system from actions taken by subscribers and management/control of external systems; and 6) separate systems placed under common management/control, thus becoming the same system.

By combining these two measures, it is possible to derive a spectrum of interoperability that permits cost-versus-benefit tradeoffs. The seven levels of interoperability considered are

1) separate systems $(1,1)$

2) shared resources $(1,2)$

3) gateways $(2,3)$

4) multiple entry points $(2 ; 4)$
5) conformable/compatible systems $(3,4)$

6) completely interoperable systems $(3,5)$

7) same system $(4,6)$.

The numbers following the levels of interoperability indicate, first, the technical interface possibility, and second, the management/control possibility. The levels increase in interoperability as the number of the option increases. Level 1 has no interoperability between systems unless a man exchanges information in both systems. The only benefit of "shared resources" is the "economy of scale" that is gained when communications are traversing the same network or same transmission facilities. An example of shared resources would be when NATO utilizes bandwidth on the DSCS satellite as part of its own network, but does not talk to other DSCS users. Of course, there is a certain degree of "hardware" interoperability required for the transmitted signals to be at the correct frequencies and proper power levels.

A true, but low level of "communications" interoperability would be achieved when a few, perhaps expensive, gateways are employed. With these gateways, it is possible to cross over from one system to another and permit the subscribers in one system to access subscribers in the other system. But in this case, there are a very limited number of places where this transition occurs, usually at major nodes.

As the number of gateways increases, the level of interoperability moves up the scale to multiple entry points. Twelve to 20 gateways would be required to reach the level of interoperability classified as multiple entry points. The number of gateways is increased primarily to enhance survivability.

Conformable/compatible systems are still a higher level of interoperability. This level does not demand that the systems be identical, but it does mean provisions have been made for one system, at least, to accept the characteristics of the other 
systems so that it will be easy to transition from one system to the other at the information transfer interfaces.

A still higher level of systems interoperability would be defined as completely interoperable systems. Different hardware designs/fabrications are possible, but they require the system control elements to talk to each other; they also require an identical set of signaling formats and preemption protocols. In this case, it is possible to cross from one system to another at any point in either system; all that is necessary is to make a connection. With this level of interoperability, it could be possible for one system to cause the other system to crash or to be overloaded. This consideration is important to the decision to make systems completely interoperable.

The highest level of interoperability, of course, would be the integration of separate systems into one system. In this case, all resources are under the same management/control. This could also allow the easy interchange of equipment and the utilization of common supply systems and training facilities.

The level of interoperability may not be the same for each of the services (i.e., voice, data) that a system provides its subscribers. Therefore, it is necessary to treat each service separately, resulting in the matrix presentation shown in Fig. 6. If it were possible to evaluate each service of System A on how well it interoperates with the comparable service in the DCS, its overall interoperability could be summarized by Fig. 7 . An example of how the matrix might be used in the architectural efforts is shown in Fig. 8. The goal capability could be hypothesized as shown and the cost-versus-benefit tradeoff performed to determine the desirability of achieving the goal.

Systems have been connected in the past, and many of the different levels of interoperability shown in Fig. 8 have been obtained. Particularly with analog systems, it has been quite feasible to accomplish this. As we move into the digital world, it is important to be able to continue to achieve system interoperability at varying levels. Flexibility becomes an important issue in establishing the level of interoperability between two digital systems. A middle level of interoperability (i.e., multiple entry points) can be implemented by either expanding the number of gateways or by managerially placing constraints on systems that have the inherent capability to achieve high levels of interoperability. Obviously, the second approach is more flexible if a crisis or policy change should dictate the need for an increased level of interoperability.

\section{ESTABLISHING INTEROPERABILITY GOALS/ SECURE VOICE COMMUNICATIONS}

It should now be apparent that there is a well-stated need for telecommunications interoperability between certain communities of interest. However, the lack of a measure of interoperability by which to state goals for specific systems, and the lack of persistent pressures by a higher level system manager during the design of subsystems, has resulted in inadequate levels of interoperability. When proper consideration is given to interoperability during the early phases of design, interoperable modes can be established at little additional cost, even when the implications of security and survivability are factored in. Therefore, it is important to establish interopera-

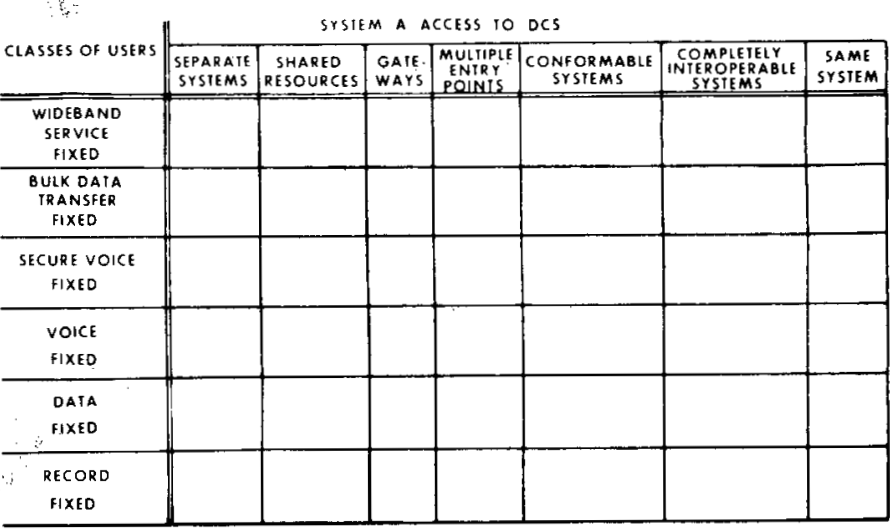

Fig. 6. Interoperability matrix.

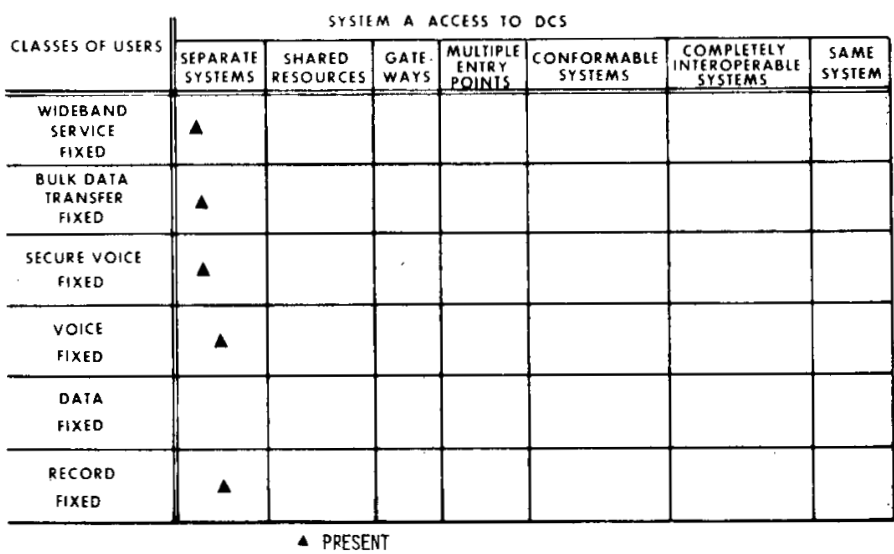

Fig. 7. Interoperability matrix (System A access to DCS).

\begin{tabular}{|c|c|c|c|c|c|c|c|}
\hline \multirow{2}{*}{ CIASSES OF USERS } & \multicolumn{7}{|c|}{ SHSEMA ACCESS TO DCS FULRE. } \\
\hline & $\begin{array}{l}\text { SEPARAIE } \\
\text { SYSTEMS } \\
\end{array}$ & $\begin{array}{c}\text { SHARED } \\
\text { RESOURCES }\end{array}$ & $\begin{array}{l}\text { GAAE- } \\
\text { WAYS } \\
\end{array}$ & $\begin{array}{l}\text { MutPipte } \\
\text { ENIR } \\
\text { POINIS }\end{array}$ & $\begin{array}{c}\text { CONF ORMABIF } \\
\text { SYSIIEMS }\end{array}$ & $\begin{array}{l}\text { COMPLETEL } \\
\text { INEROERABL } \\
\text { SYITEMS }\end{array}$ & $\begin{array}{r}\text { SAME } \\
\text { SYSIEM }\end{array}$ \\
\hline $\begin{array}{c}\text { W:DEBAND } \\
\text { SERVICE } \\
\text { FIXED }\end{array}$ & $\bullet$ & - & & & - & & \\
\hline $\begin{array}{c}\text { BULK DATA } \\
\text { TRANSFER } \\
\text { FIXED } \\
\end{array}$ & $\Delta \bullet$ & $\bullet \cdot$ & & & - & & \\
\hline $\begin{array}{l}\text { SECURE VOICE } \\
\text { FIXED }\end{array}$ & $\Delta \bullet$ & - & $\rightarrow$ & $\longrightarrow$ & 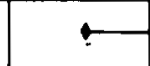 & & \\
\hline $\begin{array}{l}\text { VOICE } \\
\text { FIXED }\end{array}$ & $\Delta$ & 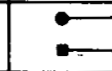 & $\Leftrightarrow$ & $\Leftrightarrow$ & 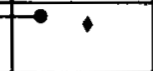 & & \\
\hline $\begin{array}{l}\text { DATA } \\
\text { FIXED }\end{array}$ & & $\because$ & & & $\bullet$ & & \\
\hline $\begin{array}{l}\text { RETORD } \\
\text { FIXED }\end{array}$ & $\Delta$ & $=$ & $\Leftrightarrow$ & $\Rightarrow$ & $\longmapsto$ & $\longrightarrow$ & \\
\hline
\end{tabular}

Fig. 8. Interoperability matrix (System A access to DCS [future]).

bility objectives in measurable terms and assure compliance through the operational and developmental phases of a system.

The operational phase is important since it is the period when operational procedures and software are adapted to comply with the mission as perceived by the operating manager. Unless configuration control is maintained and frequent testing is performed (joint exercises), even the TRI-TAC equipment could become noninteroperable as it is assimilated into the different organizations. Stress should be placed on establishing the minimum number of interoperable modes that satisfy interoperability objectives. This permits the highest 
possible level of autonomy for the subsystems and prevents burdening individual equipment with unnecessary complexity.

Nowhere has a lack of interoperability been a greater problem to the Defense Department than in the secure voice area. The difficulty of the technical problems when confronted by the several communications communities each with its own peculiar constraints has led to rather different systems being fielded, resulting in severe interoperability problems. A major contribution to these problems is the fact that secure voice quality degradation often occurs when systems using disparate voice processing algorithms are interfaced. The Worldwide Secure Voice Architecture (WWSVA) [5] is the name given to an effort to develop an approach to DoD's secure voice systems to improve this situation by establishing coordinated evo. lutionary approaches to all of the communities. The WWSVA presents a first iteration set of objectives, described in terms of the spectrum of interoperability, for the communities of interest shown in Fig. 9. The connectivities between the systems designed to support these communities of interest were determined to be as shown in Fig. 10. The Appendix presents a short description of the major system elements supporting these communities of interest; many of these systems are discusssed in greater detail in other papers in this issue. Fig. 11 shows how different the constraints are that are levied on the design of the individual systems that make up the WWSVA. These differences make it impossible to develop an optimum design that would be acceptable to all users; therefore, it is desirable to establish interoperable modes that impose the least impact on individual designs. (Fortunately, the advent of low cost microprocessors will make it much easier to arrive at acceptable solutions. By placing this additional microprocessor-derived intelligence in the terminals and in switches near the subscribers, it should be possible to develop an architecture that satisfies most of the constraints in Fig. 11.) In order to establish the WWSVA interoperability objectives, the following questions pertaining to interoperability were examined in detail in [5].

1) What is the size of the community and extent of interaction with DCS subscribers?

2) What is the geographic location of subscribers?

3) What is traffic in and among the communities of interest?

4) What is the mobility of subscribers in support of the mission and their normal deployment?

5) Is there a need for special requirements like preemption and rapid speed of service?

6) What is the existing capability?

7) Are there existing or planned programs that could preclude interoperability improvements?

8) Would it be desirable to restore service over another system to improve survivability?

9) Are there significant cost advantages to be gained by extending through another system or using another system to off-load peak traffic?

10) Does one of the other systems expect to rely on DCS links for internal command and control?

11) Is there an economic or operational advantage in providing common logistics?

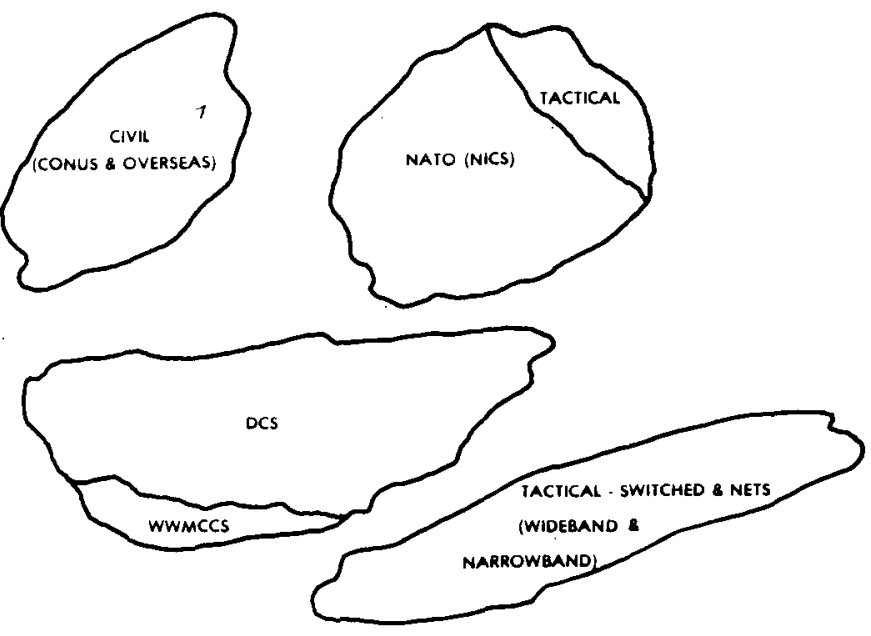

Fig. 9. Communities of interest.

12) Are there established management constraints that restrict the level of interoperability?

The resulting levels of interoperability for peacetime [dayto-day operations and crisis or support of conflict (when it is outside the immediate geographic region)] are shown in Fig. 12. The resulting levels of interoperability for conflict [theater conventional war, theater nuclear war, and strategic nuclear war (when they occur within the immediate geographic region)] are shown in Fig. 13.

Peacetime interoperability is shown pictorially in Fig. 14 . Gateways are sufficient for access into the DCS by both the CIVIL and NATO communities. Multiple entry point level of DCS interoperability is sufficient for garrisoned tactical wideband subscribers since high level commanders, who need preemption capability, are also DCS Secure Voice component (SEVOCOM) subscribers. On the other hand, tactical narrowband subscribers (i.e., Fleet Commanders) only have access to their tactical terminal and the ability to obtain preemption through the DCS is necessary. Therefore, the tactical narrowband subscriber requires a DCS interoperability level of completely interoperable.

The levels of interoperability required to respond to conflict, as shown in Fig. 15, are significantly different from those for peacetime. For survivability reasons, it would be advantageous to increase the level of DCS interoperability for the CIVIL and NATO communities to conformable systems. The ability to reconstitute the DCS with tactical equipment, and the complete interdependence of communications networks in a theater of operations, would drive the DCS and TRI-TAC toward the highest degree of interoperability, i.e., same systems. The role of supporting communications for tactical narrow-band subscribers has not changed above that of peacetime, except to require more of the same.

The WWSVA effort examined the feasibility of achieving the desired levels of interoperability described in the previous paragraphs. One of the recurring problems is the inability to assure the use of common equipment by all secure voice subscribers. This is due to management prerogatives and different time scales for implementation. Therefore, the use of disparate equipment is accepted as a fact of life, particularly in the near to midterm, and barring extraordinary technology advances, 


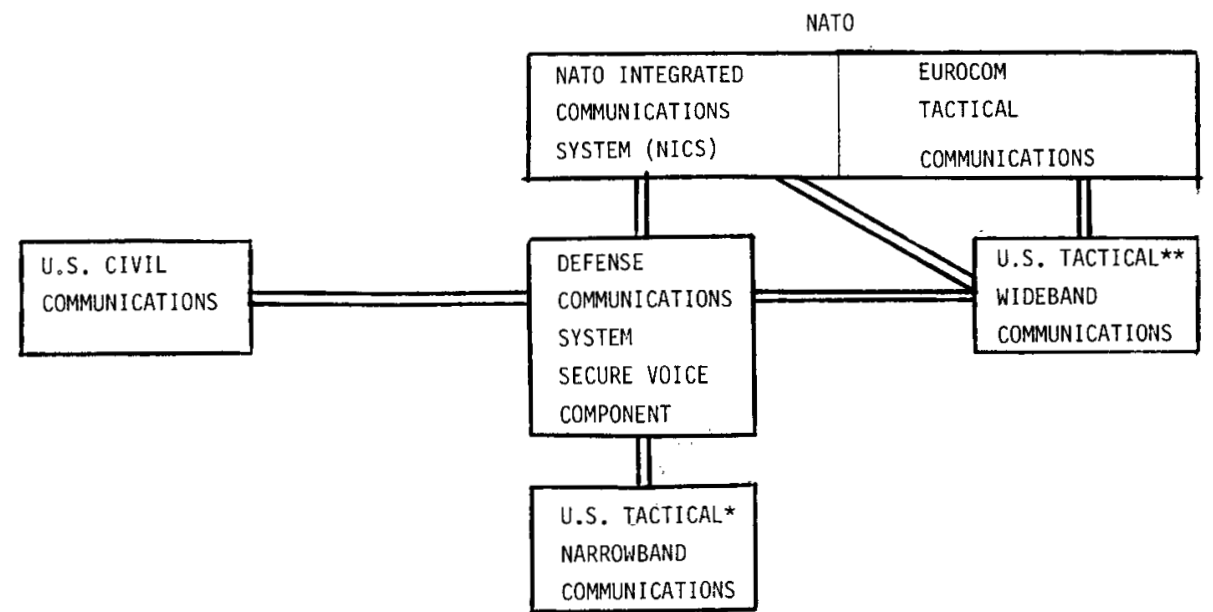

* Communications that utilize constrained channels such as high frequency (HF) propagation.

** Communications that are not physically constrained by the transmission channel.

Fig. 10. Interoperability of WWSVA communities.

\begin{tabular}{|c|c|c|c|c|}
\hline COMMUNITY & $\begin{array}{l}\text { DATA RATE } \\
\text { CONSTRAINTS }\end{array}$ & $\begin{array}{l}\text { PHYSICAL } \\
\text { CONSTRAINTS }\end{array}$ & QUALITY & $\begin{array}{l}\text { DOMINANT } \\
\text { CONSTRAINTS }\end{array}$ \\
\hline Tactical Narrowband & $\leq 2.4 \mathrm{~kb} / \mathrm{s}$ & $\begin{array}{l}\text { Moderate size, } \\
\text { weight, power }\end{array}$ & Good intelligibility & Data rate \\
\hline Tactical Wideband & $\begin{array}{l}\text { Can be as high } \\
\text { as tens of } \mathrm{kb} / \mathrm{s}\end{array}$ & $\begin{array}{l}\text { Small size, iow } \\
\text { power, low cost }\end{array}$ & Good intelligibility & Size, weight, power \\
\hline Civil & $\begin{array}{l}\text { Limited by VF } \\
\text { channels of civil } \\
\text { networks }\end{array}$ & $\begin{array}{l}\text { Office environment, } \\
\text { convenience of use }\end{array}$ & $\begin{array}{l}\text { Good intelligibility } \\
\text { and quality }\end{array}$ & $\begin{array}{l}\text { Use with civil } \\
\text { networks }\end{array}$ \\
\hline DCS & $\begin{array}{l}\text { Limited by VF } \\
\text { channe } 15 \text { of civil } \\
\text { and military net- } \\
\text { works }\end{array}$ & $\begin{array}{l}\text { Office environment, } \\
\text { moderate cost, } \\
\text { convenience of use }\end{array}$ & $\begin{array}{l}\text { Good quality and high } \\
\text { intelligibility }\end{array}$ & $\begin{array}{l}\text { Interoperability } \\
\text { with above } \\
\text { communities }\end{array}$ \\
\hline NATO (NICS) & Similar to DCS & Similar to DCS & Similar to DCS & SimiTar to DCS \\
\hline
\end{tabular}

Fig. 11. Design constraints.

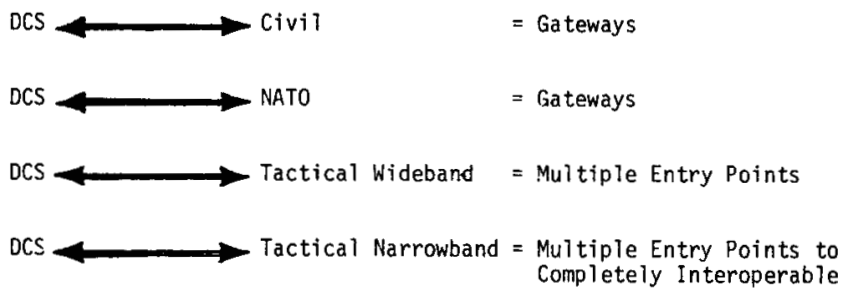

Fig. 12. Peacetime interoperability objectives.

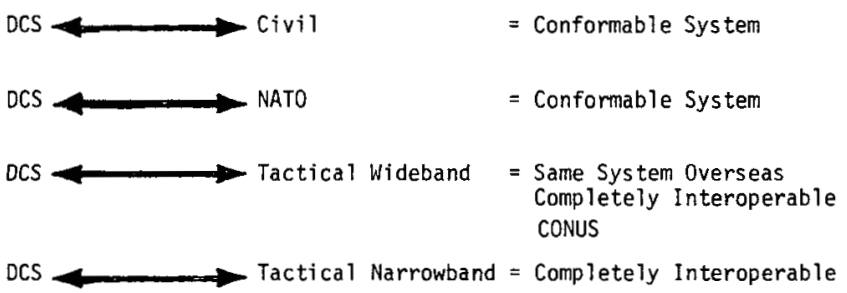

Fig. 13. Conflict interoperability objectives. even the future architecture must provide a mode of operation that will accommodate various secure voice terminals.

Currently, several communities use a variety of terminals at several data rates. The DCS with the greatest interoperability burden uses a combination of high quality PCM terminals and low quality channel vocoders, the former serving as the vehicle for interoperability, through tandem connections. However, the cost of the $50 \mathrm{kbit} / \mathrm{s}$ circuits limits their number. Also, the limited number of potential transmission paths for the wide-band service impacts survivability. Poor response time can normally be expected, except for nearly instantaneous service provided to a few selected subscribers. The difficulty in using the system also reduces the users' acceptance of the service. In order to fill the urgent need for expanded service, many new secure voice terminals using disparate algorithms are in the process of being fielded by the user. This proliferation of terminal types will cause serious interoperability problems.

The midterm (around 1985) secure voice capability will 


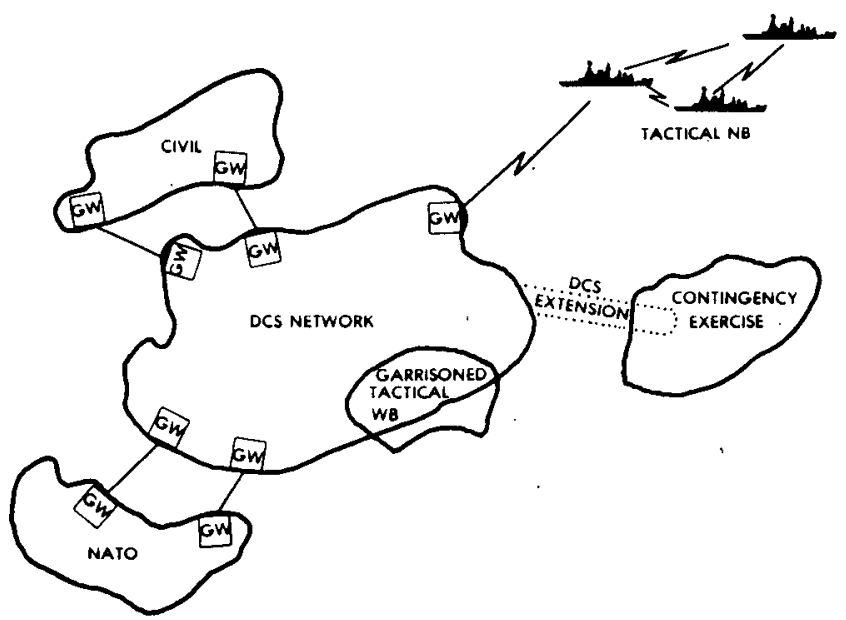

Fig. 14. Peacetime interoperability connectivities.

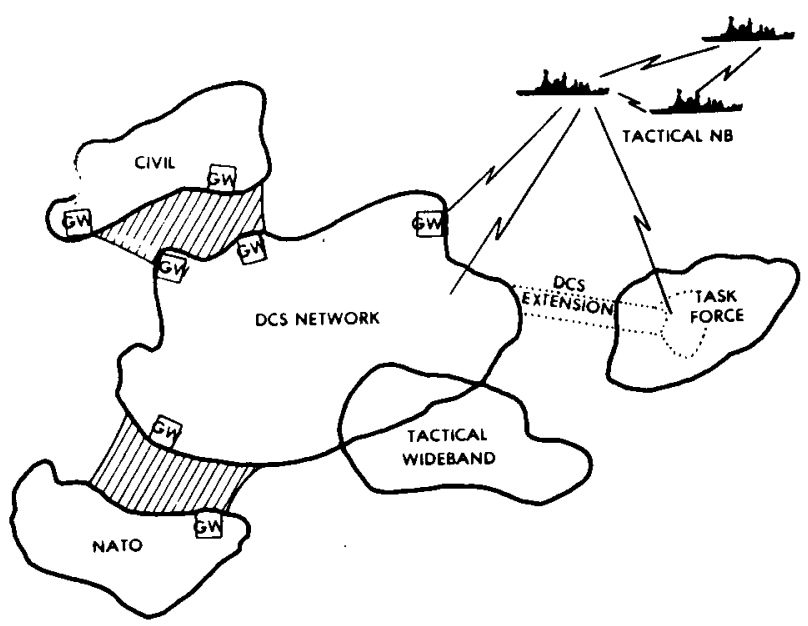

Fig. 15. Conflict interoperability connectivities.

provide service to many more users with generally improved response times and better quality. However, the proliferation of terminal types will intensify the interoperability problems, and the resulting quality will not be equal to that of the clear voice service. Secure voice will be transmitted at primarily four rates $(2.4,9.6,16$, and $32 \mathrm{kbits} / \mathrm{s})$. The 16 and $32 \mathrm{kbit} / \mathrm{s}$ rates will serve the wide-band tactical community with their primarily digital facilities derived from the TRI-TAC program. The terminals realizing these rates use the CVSD processing technique. They are small, consume very little power, and are thus compatible with the environment. A rate as high as 32 $\mathrm{kbits} / \mathrm{s}$ is required, despite its wide-band width requirement, to achieve adequate quality in this environment. The narrowband tactical community will rely on the linear predictive vocoder at $2.4 \mathrm{kbits} / \mathrm{s}$ to match the primary data rate constraint of the HF communications media. The DCS will use three rates, $2.4 \mathrm{kbit} / \mathrm{s} \mathrm{LPC}, 16 \mathrm{kbit} / \mathrm{s}$ CVSD, and $9.6 \mathrm{kbit} / \mathrm{s}$ adaptive predictive coding (APC). The latter achieves good voice quality and is expected to be the primary mode of operation. The $2.4 \mathrm{kbit} / \mathrm{s}$ rate serves as a backup for circuits which will not support the $9.6 \mathrm{kbit} / \mathrm{s}$ rate and also to provide interoperability with the narrow-band tactical users. The essential purpose of the $16 \mathrm{kbit} / \mathrm{s}$ mode is to achieve interoperability with the wide-band tactical community. All three rates will be im- plemented in quasi-analog form using modems over analog AUTOVON. Interoperability problems will still exist between the majority of subscribers described above and those systems that utilize the earlier generation terminals. To help accomplish a graceful transition, it may be necessary to retain the wideband PCM capability for some time.

The goal architecture of the 1990's assumes that the above four-rate architecture can be reduced to two rates. First, the voice processing and microprocessor state-of-the-art should permit the development of a $16 \mathrm{kbit} / \mathrm{s}$ terminal with the quality of $32 \mathrm{kbit} / \mathrm{s}$ CVSD. Second, the DCS, following the trend of commercial switched systems, should be largely digital by that time frame, permitting this same terminal to serve the DCS community and the eventual phaseout of the $9.6 \mathrm{kbit} / \mathrm{s}$ rate. The $2.4 \mathrm{kbit} / \mathrm{s}$ rate will remain in the dual role of serving the narrow-band tactical forces and as a highly robust backup for the higher rate. Conceivably, the pace of technology could permit the achievement of the goals of the $16 \mathrm{kbit} / \mathrm{s}$ terminal at a lower rate (say $8 \mathrm{kbits} / \mathrm{s}$ ). It appears unlikely, however, that the requisite quality will be achievable at $2.4 \mathrm{kbits} / \mathrm{s}$ to permit a common algorithm, single rate system.

The architecture outlines a feasible transition strategy to evolve from the near and midterm capability of independent networks that exhibit a low level of interoperability, primarily separate systems and gateways, to an architecture that integrates the two standard elements described above to achieve the potential for a "completely interoperable" level of interoperability for most subscribers. A high level of interoperability with the clear voice subscribers will also exist since the DCS secure voice capability will be integrated into the AUTOVON.

The WWSVA analysis determined that it was impractical and unnecessary to expect the goal architecture to achieve a level of interoperation of "same system" that would be managed by a single manager. However, by capitalizing on new technology and moving the intelligence in the system closer to the user, with a modular switching capability it will be possible to achieve many of the advantages of a "same system" architecture. This is accomplished by careful planning and coordination to make proper use of the distributed system capability to reduce response times and costs, and to also improve the ability to restore service over other networks. Survivability is enhanced by providing the capability to obtain interfaces with other networks at or near the subscriber; this capability presents the greatest number of possibilities for diverse routing.

\section{CONCLUSIONS}

1) There is a well-established need for telecommunications interoperability between certain communities of interest; however, the current levels of interoperability are not adequate, and the situation could get worse unless exceptional management is initiated.

2) The requirements and interoperability considerations between the different communities are so drastically different, particularly during peacetime, that it is unrealistic to expect the communities to accept the same systems.

3) To provide manageable entities and reasonable realms of 
responsibility, again particularly in peacetime, it is desirable to provide the highest possible degree of autonomy for the individual systems.

4) Since the individual system designers will be designing their systems to different criteria, only one of which is interoperability, it is important to reduce the number of interoperable modes to a minimum.

5) Interoperability goals should be established early and expressed in measurable objectives and terms that are understood.

6) Provision must be established to assure that the objectives are achieved in the design phase and maintained throughout the operational life of the system.

\section{APPENDIX}

\section{SYSTEM DESCRIPTIONS}

\section{Strategic Systems}

Supporting the National Command Authorities (NCA) in control of the Armed Forces is the National Military Command System (NMCS). The NMCS consists of the National Military Command Center (NMCC), the Alternate National Military Command Center (ANMCC), and the National Emergency Airborne Command Post (NEACP), with their interconnecting telecommunications and ADP support. These facilities receive, evaluate, and display intelligence, warning, and force status information, and direct and control the forces in carry. ing out national decisions.

Worldwide Military Command and Control System: The President needs a responsive, reliable, flexible, and survivable command and control system to serve the NCA in all types of military operations. This is provided by the Worldwide Military Command and Control System (WWMCCS), which incorporates a number of unique and independent command, control, and communications $\left(\mathrm{C}^{3}\right)$ systems to assure better connectivity with the strategic forces.

Minimum Essential Emergency Communications Network (MEECN): MEECN spans the entire radio frequency spectrum from ELF through SHF to provide the connectivity, redundancy, and flexibility needed for the command and control of the strategic submarine, bomber, and ballistic missile forces.

Defense Communications System (DCS): The DCS is a general-purpose system composed of Government-owned and leased transmission media, relay stations, and switching centers. The system embraces all of the long haul point-to-point DCS assets of the Army, Air Force, Navy, and Marine Corps. Service to customers is provided primarily through common user switched networks. These networks include AUTOVON, AUTODIN, and AUTOSEVOCOM. Each of these networks is characterized by a degree of automatic switching, a military precedence system, worldwide trunking, and service to a large community of Defense and other U.S. Government users. However, the DCS also provides special communications services for certain classes of high priority customers requiring immediate responsive command and control communications. The DCS specifically does not include air-to-air, ship-to-ship, air/ground, or ship-shore communications, nor those broadly defined as tactical, except in support of the NCA or unified or specified commanders.

\section{Tactical Systems}

Tactical $\mathrm{C}^{3}$ systems must operate in an integrated fashion with sensor and intelligence systems to provide timely warning, responsive control of forces, and assessment of operations. Those functions are essential to creating a highly integrated, mobile, and capable fighting force. Our individual weapons systems and those of our Allies will be insufficient to engage the larger number of similar Soviet systems effectively unless they operate as a cohesive combined arms team [1].

Joint Tactical Communications Program (TRI-TAC): TRI-TAC will provide common multichannel communications equipment for all the Services. The equipment will be mobile, secure, survivable, and capable of rapid dissemination of messages and voice communications using automatic switching. Interoperability throughout the theater will be ensured by the use of TRI-TAC common equipment, which will also provide interfaces between single channel tactical users and other theater systems, as well as between United States and Allied systems. The individual TRI-TAC development programs are divided among the Services and are well underway with some operational testing in progress [1].

Combat Net Radio: Close to the Forward Edge of the Battle Area (FEBA), command and control are exercised primarily through the use of combat net radios. The Army is the leading service in developing a family of jam-resistant, manpack, vehicular, and airborne $F M$ radios in the VHF frequency range for all the Services. The program, called the Single Channel Ground and Airborne Radio Subsystem (SINCGARS-V), is in development [1].

\section{Army:}

The Tactical Communications System: The backbone of the Tactical Communications System is the Corps and Divisional multichannel networks. The Tactical Communications System is formed from the Command and Area Networks which use pulse code modulation, time division multiplexing, and link encryption to encrypt the multiplexed signal. For transmission of the multiplexed signal, either cable, line of sight radio relay, or tropospheric scatter equipment is used. The Command Multichannel System is a point-to-point network connecting the Corps and Divisional Headquarters to the Maneuver, Fire Support, and Combat Support Units. The Corps Area Multichannel System is a network interconnecting the Corps Area Signal Centers (nodes). The Corps Area Multichannel System interconnects each Corps Area Signal Center (node) with at least two other centers (nodes). The locations of Area Signal Centers are selected to permit service to units within geographical areas. The Command Signal Centers are located to serve the Corps Headquarters echelons. The Area Signal Centers contain the radio and multiplex equipment which interoperates with the multichannel systems, voice switching and terminal equipment, teletypewriter terminal equipment, facsimile equipment, tape relay facilities, messenger elements, and communications control elements. The future Army system is the Integrated Tactical Communica- 
tions System (INTACS). This system architecture, adopted by the Army in 1976, integrates equipment provided through such programs as TRI-TAC, the Single Channel Ground and Airborne Subsystem (SINCGARS), and the ground mobile forces tactical satellite communications (GMF-TACSATCOM) system. The integration of these systems, along with the Army portion of the Joint Multichannel Trunking and Switching System (JMTSS), will support interoperable communications for the theater ground forces operations, even in remote areas [1].

\section{Navy:}

Naval Telecommunications System (NTS): The NTS is a complex of terminal, transmission, switching, cryptographic, and control devices that collectively provide the electrical and optical communications capability for the exercise of command and control over the naval operating forces, for the transmission of operational information to and between units of such forces, and for the administration of forces, shore establishments, and other components of the Navy.

Organizationally, the NTS provides electrical and optical communications from the Commander in Chief and naval commanders to and down through all naval forces under their command.

Conceptually, the NTS includes portions of the DCS transmission systems and the National Communications System (NCS) and the DCS switched networks, as well as fleet support nets (broadcast, ship-shore, air-ground) and direct interunit fleet nets. Most of the shore establishment is served by the DCS, not by the NTS.

For definition and system engineering purposes, the NTS includes all end terminal processing equipments necessary for the communications function of end-to-end information and data transfer. This includes all media for the transmission, emission, and reception of signs, writing, images, and sounds or information of any nature by wire, radio, visual, electromagnetic, electrooptical, or acoustical systems. Unless specifically exempted, all such systems afloat, ashore, and airborne are considered to be a part of the NTS.

Naval forces must operate in all tactical environments: air, sea, subsurface, amphibious, and shore. This diversity of operating environments has created the need for a broad range of systems and equipment to provide the required $\mathrm{C}^{3}$ capability. The Fleet Satellite Communications system (FLTSATCOM) is being developed. It will permit jam-resistant fleet broadcast and two-way communications between naval aircraft, ships, submarines, and land-based facilities, and as such will be the backbone of the NTS. These NTS systems will accommodate the expanded communications requirements necessitated by more capable weapons systems and will improve the NCA's capability to exercise command and control of U.S. forces throughout all levels of conflict [1] .

Marines: From 1979 to 1980, the Marine Corps Communications System will remain primarily an analog system. At lower combat units, VHF-FM single channel radios are predominant. Improved devices for data processing are being introduced for record, narrative, and graphic traffic. Substantial COMSEC equipment is also being introduced for voice traffic during this time frame. Communications Centrals function as the transmission and reception point for teletypewriter operations and provide for torn tape relay between senior commands and subordinates. The introduction of some automatic telephone switching provides improved service to telephone subscribers. Manual switchboards remain in use to service those smaller communities of subscribers where switching speed is not critical. Multichannel transmission systems are available for relatively static command posts.

In the 1985 time frame, the Marine Air Ground Task Force (MAGTF) will require totally secure telecommunications systems with multichannel trunking, narrow-band capability for all HF circuits, and wide-band for all VHF and UHF circuits. A mixture of analog and digital equipment will exist. In this time frame, the Tactical Data Systems (TDS's) [the Marine Tactical Command and Control Systems (MTACCS)] will be entering the field. These systems will require a significant data transfer capability. Satellite communications will also be introduced into the field at this time. Secure voice telephone operations will continue to be satisfied by the KY-65 (PARKHILL) and the newly introduced Digital Subscriber Voice Terminal (DSVT) (KY-68) and ANDVT. The MAGTF's will require fully secure, highly reliable, automatic digital switching devices to handle both narrative and data traffic.

Air Force: Air Force communications are normally air-toair and air-to-ground and in support of specified commands such as SAC and NORAD. However, the Air Force has an important role in theater air defense and close air support and interdiction. Therefore, the majority of Air Force communications is point-to-point, with an emphasis on radio links. The Air Force makes extensive use of the HF and UHF bands and relies heaviliy on the tactical satellite capability. It does, however, utilize the DCS for many normal operations including sensor nets, logistic and personnel nets, and certain command and control functions.

The SAC Warning and Control System (SWCS) is a real-time processing and display system which enables actions by the SAC Commander in Chief, upon receipt of missile attack information, to protect his forces pending decisions by the NCA. Attack information is received over high-speed communications links from several warning sensors operated by NORAD such as the Satellite Early Warning System, the Ballistic Missile Early Warning Systems, and the Sea-Launched Ballistic Missile Detection and Warning System. The hardware and software of the SAC warning and control system are continually upgraded to maintain state-of-the-art capabilities in conjunction with and compatible to sensor improvements.

Survivable two-way communications in SAC have global dimensions, with satellite communications systems playing an important role in fully satisfying this continuing requirement. The Air Force Satellite Communications (AFSATCOM) program will provide two-way record (teletype) communications between a family of airborne and ground terminals by special transponders which are installed "piggyback" on the DoD host satellites.

The Data Transmission Subsystem (DTS) of the SAC Automated Command Control System is to be replaced by the new SAC Data Network (SACDIN). SACDIN will be a record data 
communications system which is faster and more accurate, has a larger message-handling capacity, a higher degree of survivability, and which offers greater reliability than the present DTS. In addition, it will extend two-way automatically encrypted communications to all existing missile launch control centers for the first time. The system will be interoperable with AUTODIN and AFSATCOM, and it will offer multiple new ground entry points for communicating with the Airborne Command Post (ABNCP) battle staffs [3]

\section{NATO Integrated Communications System (NICS)}

In the late 1960's, the Allies recognized their communications inadequacy. In 1970, they initiated a program to construct a NATO Integrated Communications System-the NICS-which was then the largest single program to be undertaken by the Alliance. The NICS will, in time, provide modern communications satisfying the full range of military and political requirements. The NICS Management Agency (NICSMA), located in Brussels, is procuring and installing this new system. It will be operated for the most part by the NATO military commands.

NATO is implementing the NICS in two stages. The first step has been called the "independent networks." It will have the following capabilities:

1) a network of store-and-forward message switches, called the TARE network

2) a network of voice switches, called the Initial Voice Switch Network-IVSN

3) a small secure voice network, called by NATO the Pilot Secure Voice Program.

Also included as part of Stage I of the NICS are two major supporting programs. One is expansion of the satellite communications system to provide transmission links throughout the Alliance, and the other is the Subsystem Integration Program.
The NICS Stage II Architecture is in the concept formulation phase.

\section{REFERENCES}

[1] D. H. Rumsfeld, Annual Defense Dep. Rep. FY 1978, Secretary of Defense

[2] " $\mathrm{C}^{3}$ architecture and interoperability," J. Armed Forces Electron. Ass. (SIGNAL), vol. 32, p. 67, Aug. 1978.

[3] Command and Control Issue, J. Armed Forces Electron. Ass. (SIGNAL), vol. 31, Mar. 1977

[4] D. H. Rumsfeld, "A C $\mathrm{C}^{3}$ overview," 30th Anniversary Issue, J. Armed Forces Electron. Ass. (SIGNAL), vol. 30, p. 34, May/June 1976.

[5] Worldwide Secure Voice Architecture (WWSVA) (S), DCA Publ., Jan. 1979.

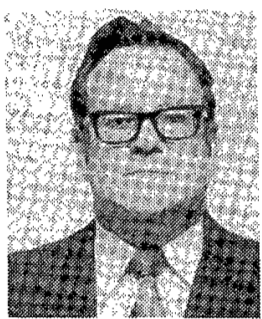

Gilbert E. LaVean (S'55-M'58) was born in Saranac, MI, on May 17, 1933. He received the B.S. degree in electrical engineering from Michigan State University, East Lansing, in 1956 and the M.S. degree, also in electrical engineering, from Drexel University, Philadelphia, PA, in 1961.

In 1956 he was employed by the Bendix Missiles Division as an Electrical Engineer. From 1958 to 1961 he was a member of the Technical Staff of the Advanced Concepts Department of the Martin Company where he developed advanced ECM and ECCM concepts. At Bendix Systems Division from 1961 to 1965 he was Group Leader for system test and evaluation of communication satellite systems. In 1965 he joined Electronic Communications, Inc. (ECI) where he became Manager of Advanced Systems and performed studies on AABNCP, AWACS, and developed tactical satellite systems. Since 1970 he has been employed by the Defense Department at the Defense Communications Engineering Center of DCA, Reston, VA, where he has held positions as the Deputy Chief Satellite Division, Associate Director Engineering Planning, and Chief Systems Engineering Division, and has been responsible for the system design efforts for the Defense Satellite Communications System (DSCS), the Worldwide Secure Voice Architecture (WWSVA), the Worldwide Digital System Architecture (WWDSA), and the Defense Communications System (DCS), respectively. 